\title{
Selected Topics on Advanced Methods in Complex Systems Research: Editorial Introduction to Issue 28 of CSIMQ
}

\author{
Erika Nazaruka* \\ Department of Applied Computer Science, Riga Technical University, \\ 10 Zunda krastmala, Riga, LV-1048, Latvia \\ erika.nazaruka@rtu.lv
}

Modern systems are quite diverse nowadays. They can vary from unique systems of systems [1], which operate with multiple data and information flows, to similar content mobile applications that may differ, slightly, in functions they implement but, greatly, in their qualitative characteristics. Evaluation of the current state of complex systems, as well as their potential modifications may touch different aspects such as prediction of systems behavior under certain conditions, analysis of the current state of the systems' components as well as providing stability to their qualitative characteristics. The functionality of a growing number of mobile applications on the market requires monitoring in cases where there is development of a new application or evolution of an existing product. Aadvanced means such as quality assurance techniques, content analysis and rating scales for mobile applications [2], blockchains [3], etc. can be used to make the processes of evaluation, monitoring, design and modification more organized and transparent.

The articles, which have been recommended by reviewers for this issue of CSIMQ, present contributions which evaluate the application of advanced means for evaluation, monitoring, design, and modification of complex systems and mobile applications with similar content. The focus of the articles presented is on the adaptation of the above-described means for new contexts and challenges.

The first article "Quality Assurance in Big Data Engineering - A Metareview" authored by Daniel Staegemann, Matthias Volk, and Klaus Turowski presents a meta-review of the current state of quality assurance in processing big data. Processing includes such activities as data storing, creating, updating, deleting, analyzing, and presenting. As a result of the systemic review of complete and relevant information sources, the authors have been able to identify mature aspects of the quality assurance in big data engineering as well as challenges that still exist and directions for possible research. The authors' findings indicate that the main focus is still on benchmarking. However, yet, there is no universal benchmarking. Interest in testing activities continues to grow and remains an open area for research.

The second article "Development and Demonstrational Instantiation of a Method for Structured Content Analyses of Smartphone Apps" by Tobias Weiss and Susanne Strahringer describes the authors' method for systematic content analysis of the content and functions of smartphone

\footnotetext{
* Corresponding author

(C) 2021 Erika Nazaruka. This is an open access article licensed under the Creative Commons Attribution License (http://creativecommons.org/licenses/by/4.0).

Reference: E. Nazaruka, "Selected Topics on Business Informatics Research: Editorial Introduction to Issue 28 of CSIMQ," Complex Systems Informatics and Modeling Quarterly, CSIMQ, no. 28, pp. I-II, 2021. Available: https://doi.org/10.7250/csimq.2021-28.00
}

Additional information. Author's ORCID iD: E. Nazaruka - https://orcid.org/0000-0002-1731-989X, PII S225599222100158X. Received: 24 October 2021. Available online: 31 October 2021. 
applications. The authors indicate that, due to the enormous number of mobile applications for the same purposes, it is hard to analyze the content and functionality of each of them by installing and experimenting with their functionality. Therefore, the authors propose adaptation of existing systematic content analysis methods based on evaluation of description of the content and functions and subjective evaluation of other users. The application of the proposed method is demonstrated in the article. This method can reduce the time necessary for market research and focus attention on products more valuable for further investigation.

The third article, entitled "Applicability of Blockchain Technology in Securities Settlement", by Janis Bauvars presents the blockchain architecture model and node linkage structure for securities settlements. The proposed model is based on the analysis of issues in securities settlements taking into account the existing literature on financial markets, Central Securities Depositories Regulation and applicability of different principles of blockchain technology for this field. Characteristics of the proposed model are evaluated against scholars' expected benefits and drawbacks of using blockchain for securities settlement and cross-border settlement efficiency. As the author mentions in the article, the results of the evaluation illustrate potential benefits in solving some of the current securities settlement issues such as costly reconciliation and difficult crossborder securities settlement. However, the author doubts that practical implementation without market-wide commitment will be fast and easy.

The CSIMQ editorial team would like to thank all the authors for their contribution and all the reviewers of this issue for their valuable comments and recommendations on improvement regarding the submitted articles.

\section{References}

[1] J. Ladyman, J. Lambert, and K. Wiesner, "What is a Complex System?" European Journal for Philosophy of Science, vol. 3, pp. 33-67, 2013. Available: https://doi.org/10.1007/s13194-012-0056-8

[2] Y. Terhorst, P. Philippi, L.B. Sander, D. Schultchen, S. Paganini, M. Bardus, et al, "Validation of the Mobile Application Rating Scale (MARS)." PLOS ONE, vol. 15, issue 11, pp. 1-14, 2020. Available: https://doi.org/10.1371/journal.pone.0241480

[3] M. N. M. Bhutta et al., "A Survey on Blockchain Technology: Evolution, Architecture and Security," IEEE Access, vol. 9, pp. 61048-61073, 2021. Available: https://doi.org/10.1109/ACCESS.2021.3072849 